\title{
THE DESIGNER'S ROLE IN REVITALIZED PARTICIPATORY DESIGN AGENDAS
}

\author{
Bernardo Alves Villarinho Lima and Leonelo Dell Anhol Almeida \\ Postgraduate Program in Technology and Society (PPGTE) - Federal University of Technology, Paraná (UTFPR) \\ Av. Sete de Setembro, 3165. Curitiba, PR - Brazil
}

\begin{abstract}
Over the last four decades, Participatory Design (PD) gained traction in Human Computer Interaction (HCI) communities around the world. The discipline became recurrent in HCI publications, the tools and methods it offers present alternatives in attempts to design with persons, and not only for them. The PD research community is challenged by the notion that current practices focus on the production of artifacts, rather than designing for democracy and empowerment of partner communities. Countering technocratic trends, researchers around the world seek to renew the discipline by proposing alternative research agendas, towards a critical and politically engaged discipline. Designers present themselves as actors and actresses in these processes, and understanding how they operate can inform future works on how design practices can promote empowerment despite the power gap between participants and designers. This paper explores papers from the 2018 Participatory Design Conference (PDC), seeking state-of-the-art on how researchers perceive themselves in their practices, and proposes a set of suggestions on how to plan participation in a situated manner.
\end{abstract}

\section{KEYWORDS}

Participatory Design, Science, Technology and Society Studies, Critical Theory of Technology

\section{INTRODUCTION}

Participatory Design (PD) presents itself as an alternative to revert scenarios of disempowerment that entail the introduction of computational artifacts in living and work spaces (Bødker and Kyng 2018). The research field and development approach started in Scandinavian countries with a political commitment, which sought to support workers amidst rapid changes in technology occurring during the seventies (Emspak, 1993). Researchers and developers, referred to as designers, held the conviction that projects guided by strong partnerships between design teams and the communities that are affected by technological change would lead to improvements in the communities' quality of life and work (Bjerknes and Bratteteig, 1995) (Sundblad, 2011). Participation in projects rely on the application of methodological procedures that seek to involve stakeholders actively and directly, the procedures are termed Participatory Practices (Muller et al., 1997).

Among the contributions of the pioneering generations in PD were the use of prototypes of varied fidelities in different stages of development, and techniques for building legitimate spaces for participation and democracy. These contributions carry on to the following generations, and enable designers and partner communities to decide on technology in a meaningful and informed way. Moreover, the original co-design projects also investigated: the impact of computers in operational environments (Kensing and Blomberg, 1998); policies towards regulating technological change in work spaces; and means workers and managers can negotiate changes in productive processes (Ehn, 1990). The original participatory projects were focused on local action towards organizational policies, with an intent to side with the workers and potentially enable them to improve their own quality of life through negotiation and taking a measure of control over technological change from managers and business owners. Often, participation involved negotiation and re-design in order to build industrial spaces which accommodate both production demands and worker rights.

In its history, PD gained notoriety and its practices were appropriated by communities in diverse locales, approaching diverse research and development problems (Sundblad, 2011) (Schuler and Namioka, 1993). However, there are challenges and pitfalls, occasioned by disparities inherent to the roles of professional designer and partner community. According to Muller et al. (1997), designers can use participatory practices 
to exploit partners' work while giving no returns to their communities, and can deceive the communities in order to push their own design vision towards problems, rather than applying a collective vision.

The different needs of each community (be it designer or partner) change how PD is applied and what research and development matters it seeks. For instance, when imported to the United States from Scandinavia, PD would no longer hold worker's needs as its driving force, and would instead be driven by designing more efficient and more effective artifacts (Muller et al., 1997) (Spinuzzi, 2002). During the nineties in the US, leveraging partners' expertise in order to build better computer systems is justified by agendas that sought to improve results through artifacts, in lieu of changing politics in work environments, such as Contextual Design (Beyer and Holtzblatt, 1998). This approach adapts Scandinavian investigation and prototyping techniques in a way that discards the need to acknowledge conflicts of power inherent to technological change, imposing a technocratic vision over the introduction of new artifacts (Spinuzzi, 2002).

The beginning of the Participatory Design Conference (PDC) in 1990 promoted communication between European and North American designer communities, which contributed to an alignment of research agendas (Halskov and Hansen, 2015). Following the first PDC, the PD community's interest in making political commitments waned, not only because of the commercial results by Contextual Design and similar approaches, but also due to changes in Scandinavian politics (Bødker and Grønbæk 1992). PD during and after the nineties gained traction as a way to produce artifacts, but lost some of its original focus as a political mindset for collaboration and production of better quality of life to partner communities (Spinuzzi, 2002).

Moreover, and in spite of eventual alignments in research agendas, the development of technology and artifacts does not occur homogeneously in every designer community. The way of thinking about technology and design varies according to community and historical moment (Feenberg, 2000). There are movements that resist the alignment of research agendas. PD practitioners during the twenty-tens seek methods for promoting spaces for participation which integrate different cultural and historical situations, conflicts and contradictions as important parts of technological innovation, using disciplines beyond Computer Science and thinking beyond the introduction of artifacts (Björgvinsson et al., 2010) (Pihkala and Karasti, 2018).

Bødker and Kyng (2018) expose participatory and collaborative projects whose results bring a breath of fresh air to the discipline, and proposed a research agenda with the potential to "revitalize" it, returning PD to its roots as a way for taking political action through design. Upon the publication of the 2018 special edition of the ACM Transactions on Computer-Human Interaction, about re-thinking PD, researchers from many locales (e.g. Belgium (Huybrechts et al., 2018), Portugal (Teli et al., 2018), Australia and UK (Akama and Light 2018), China (Thinyane et al. 2018)) declared similar positionings: making a commitment to renew research agendas towards political issues relevant to their locations and communities.

Each research agenda is written in a different locale, since each community has its own thinking about PD (Halskov and Hansen, 2015). However, designers constantly have a primary role in starting PD processes (Kendall and Dearden 2018). In order to think about contextually aware design, it is necessary to consider that designers are submitted to power relations under which the act of designing operates (Feng and Feenberg 2008). Power gaps between designers and partners challenge the authenticity of participatory processes as a space for dialogue and innovation, and are a concern of the discipline (Boy, 1997).

Articulating agendas which situate design spaces and projects in society and culture, in opposition of agendas interlined by technological neutrality, present as an opportunity for the Science, Technology and Society Studies to contribute to Participatory Design (Thinyane et al. 2018) (Feng and Feenberg, 2008). Considering the designer's responsibility to promote democratic spaces, this paper presents an analysis of works from the 2018 edition of the PDC seeking to comprehend, in the state-of-the-art, how designers perceive themselves in their practices. From the findings, we also propose a set of suggestions regarding the planning of participatory practices that are aware of the designer's needs to position themselves politically.

This paper is organized as follows: section 2 exposes a comparative study of how the designer is viewed by authors of the 2018 edition of the PDC; section 3 proposes a set of suggestions for planning participatory practices; and section 4 closes this paper by presenting considerations, opportunities for future work.

\section{VISIBLE DESIGNERS IN PARTICIPATORY DESIGN}

A research agenda guides short and long term goals in research projects, by means of suggestions on what researchers must think about when making epistemological and methodological choices in their investigations. 
Composing and articulating an agenda explicitly is a relevant step on elaborating any research project. An agenda can reinforce researchers to position themselves with precision when deciding actions in investigation. Agendas indicate perspectives and political positions, and are not exempt of reproducing technocratic visions (Feng and Feenberg, 2008). PD communities in many locales sought to re-think their research agendas in order to direct their action not only towards social demands, but also towards theories and technology that enables the exercise of the partners' personal power (Korsgaard, et al., 2016).

Writing an agenda which covers theoretical, methodological and technological questions whilst still being useful is a challenge, when trying to put in perspective every aspect in research, authors leave gaps which must be taken into consideration. In this paper, we focus on the designer's role as an exercise of self-reflection, assuming that the designer has a key role in beginning and sustaining participatory projects, as the designer's expertise guides important aspects of the technology in development. The differences between designer and partner are of interest to PD researchers, since participatory practices may reproduce forms of labor division (e.g. the partner's role in Contextual Design processes), and reducing all actors and actresses in participatory projects to a single category may not be possible in most academic participatory projects, as they may be in distinct groups with diverse needs (Bødker and Kyng, 2018).

For the discussion on the designer's role, we start by the seventeen full papers in the 2018 edition of the PDC (the latest at the time of writing). The conference is a core reference for research in PD, making it representative of the state-of-the-art in PD. The event's impact means that the research agendas discussed are given visibility, and have the potential to be adopted and adapted in future works.

Due to the number of papers, and diversity of topics approached by each work, we begin investigating by reading their abstracts, their introductions, and their last sections, in order to gather a set of works with content related to the designer's role in participatory projects and practices, seeking discussions that approach designers in a directly and explicitly. We present each of the six selected articles briefly:

- Akama and Light (2018) analyse their personal experience in preparing for participatory practices, exposing a view on how a designer acts during practice. The work argues that the interactions occurring during practice are unique, and depend on the collaborating people and their cultures. The authors offer two concepts to explain difficult aspects to elucidate in participatory practices: poise, which is a practitioner's positioning on the practice; and punctuation, which is how a practitioner positions themselves in relation to the partner community;

- Huybrechts et al. (2018) explored how Hannah Arendt's reflections on the political dimension of work can be employed in designing participation projects. Arendt's concept of "action", defined as undertaking the role of a politically active citizen in society, is a guide towards discussing and building democratic spaces that outlast the designers' stay;

- Kendall and Dearden (2018) assumed that the participatory process is inherently political, and explored a historical question in PD ("Who participates with whom and what and why?"), pointing towards challenges in working with PD in developing countries, eliciting disparities between designers and partners, exposing how participation can lose its purpose due to colonial relations;

- Lodato and DiSalvo (2018) work towards stratagems for using PD in public policies, signaling three challenges that restrict the success of PD projects: the design space; economical and budget restrictions; and differences in beliefs among institutions and designers;

- Spiel et al. (2018) investigate how designers make ethical decisions in their practices, signaling that each action the designer makes has implications in the practice's results, and suggest ways for power dynamics to compromise the actualization of participation and democracy in PD;

- Thinyane et al. (2018) used the Critical Theory of Technology as a lens to discuss PD, and state that practicing the approach without reflecting about socio-economic structures may perpetuate disempowerment even in participatory processes which successfully produce artifacts. The authors expose five barriers to effective participation: language, cultural factors, power dynamics, personality traits, and knowledge of technology.

The eleven works not considered for this discussion did not approach the designer's role explicitly, focusing on other topics, such as methodology for PD projects and practices, technological education, public awareness of science, and project result reports. The texts present and elaborate on the designer's role in participatory practices and projects. Each one has a different focus, the views exposed in each work are exposed on Table 1, which also includes whether the work is oriented towards instances of practice, towards whole project lifecycles, or both. 
Table 1. An overview of the designer's role according to the selected papers

\begin{tabular}{|c|c|c|}
\hline Work & Focus & The designer's role \\
\hline $\begin{array}{l}\text { Akama and } \\
\text { Light (2018) }\end{array}$ & Practice & $\begin{array}{l}\text { Each designer is unique. Personal histories, experiences, culture, and worldviews } \\
\text { shape how they undertake challenges and practice PD. Designers configure the } \\
\text { environments for participation, and their relationships with the partner communities } \\
\text { (including mutual learning) and with their own research or products change over time } \\
\text { during a project, in a way that makes each practice also unique.The uniqueness of } \\
\text { each practice may generate unexpected situations, for which the designer must } \\
\text { respond, on the risk of compromising the entire practice. A designer's judgement is an } \\
\text { important tool, that must be used to give a practice its meaning. }\end{array}$ \\
\hline $\begin{array}{l}\text { Huybrechts et } \\
\text { al. (2018) }\end{array}$ & $\begin{array}{l}\text { Project } \\
\text { and } \\
\text { Practice }\end{array}$ & $\begin{array}{l}\text { Designers can reintegrate work and social practices, which have become distant due to } \\
\text { the current mode of production. The designer's role is to frame, support, and } \\
\text { reactivate forms of public engagement and representation. }\end{array}$ \\
\hline $\begin{array}{l}\text { Kendall and } \\
\text { Dearden }(2018)\end{array}$ & Project & $\begin{array}{l}\text { Designers are political actors and actresses, abiding not only by institutional and } \\
\text { ethical standards, but also by their own political views. A conscious effort is needed to } \\
\text { make designers and their political standpoints visible in design processes. The } \\
\text { designer acts under time and budget constraints that limit their stay in a project, but } \\
\text { they will influence the direction of the project even after they leave. The designer } \\
\text { participates into the world of the partner, and there are important ethical concerns } \\
\text { about how much it is allowable for a partner to integrate the designer's world, to } \\
\text { prevent participation from becoming exploitation. }\end{array}$ \\
\hline $\begin{array}{l}\text { Lodato and } \\
\text { DiSalvo (2018) }\end{array}$ & Project & $\begin{array}{l}\text { Institutions are constantly framing and constraining PD efforts, and designers need to } \\
\text { be aware of how they conduct the research. Strategies for participation present in the } \\
\text { literature, such as agonism, may not always be welcome in partner communities. } \\
\text { Designers are responsible for developing ways for working with their partners. }\end{array}$ \\
\hline $\begin{array}{l}\text { Spiel et al. } \\
\text { (2018) }\end{array}$ & Practice & $\begin{array}{l}\text { PD is not inherently attentive to ethics, and designers must make explicit efforts in } \\
\text { order to make ethical commitments. In conducting participatory practices, unexpected } \\
\text { interpersonal situations may happen. The way a designer deals with the unexpected is } \\
\text { essential to instancing legitimate participatory practices, as they must be careful in } \\
\text { order to avoid contradicting ethical principles. In particular contexts, designers make } \\
\text { ethical judgements continuously, as interpersonal interactions have a weight on } \\
\text { participatory practice results. }\end{array}$ \\
\hline $\begin{array}{l}\text { Thinyane et al. } \\
\text { (2018) }\end{array}$ & Practice & $\begin{array}{l}\text { The power dynamics between partners and designers, and between individuals and } \\
\text { technology are important for understanding the importance and effectiveness of a } \\
\text { participatory practice. The designer must interact and engage with partners during } \\
\text { practices, but there are barriers for promoting democratic participation and } \\
\text { empowerment that must be considered during planning. }\end{array}$ \\
\hline
\end{tabular}

The selected works inform and signal perceptions of the PD community about the designer's role as an important political agent in participation, reinforcing that the field leverages the differences between designer and partner as a factor that shapes practice. The texts point that designers positioning themselves politically have the potential to enable meaningful technological innovation by means of participation.

The selection also presents other current and important concerns of the PD community, which are linked to building spaces for participation: the project's durability; ethics in participation; communication barriers between designer and partner. The content in all six works brings a series of recommendations to support designers in thinking technological, ethical, and political matters during participatory practices. The position of each paper approaches a different part of what makes a participatory practice. It is possible, therefore, to gather their decision points and compose a comprehensive set of suggestions on how state-of-the-art PD practices can promote participation in thinking about technology beyond its materialization in artifacts, considering also the way which partners can learn how to make and maintain technology. 


\section{PRACTICING CO-DESIGN IN REVITALIZED AGENDAS}

In a current scenario of disempowerment in relation to the use, adoption and change in technological artifacts, producing technology through PD can be an alternative for communities to improve their lives whilst being out of the technology industry's agenda. Choosing a participatory approach to a problem, however, will not immediately create definitive solutions for disempowerment. Many participatory projects conclude without the desired results, and without the changes to the status quo that the approach prescribes (Bødker and Kyng, 2018). The PD community has grown conscious of the limitations in their current agendas, and by thinking about the designer inside practice spaces, it is possible to reckon how to promote participation and empowerment considering disparities between designer and partner. This section presents reflections on the reviewed works, and attempts to articulate them into a set of suggestions on factors they approach.

Upon reading all selected works, we propose a way to organize the suggestions in their agendas. Through the review, we consider three core dimensions for PD agendas: a political dimension; an ethical dimension; and a technological dimension. The dimensions we considered were based on the contents of the papers selected in the review. Bødker and Kyng's (2018) work was a methodological reference in assembling the three dimensions, and each dimension attempts to consider the PD That Matters agenda their work presents. Each dimension presents a set of suggestions towards: promoting the empowerment of partner communities; conscious choice of technology; and participation as a mutual learning process between partners and designers. These suggestions are not prescriptive or final, but may serve as a starting point for discussing the designer's role in projects and practices, and are as follows:

- Political dimension

- Building democratic dialogue spaces is as important as building artifacts: reconnecting PD to improving work and quality of life can be achieved by building democratic spaces for dialogues, that can be made to outlast the designers' stay in a community. The spaces can also be co-designed using participatory practices (Huybrechts et al., 2018b). Tackling the challenge of making a participatory project continue after designers leave the partner community is as relevant to the promotion of legitimate participations as the production of artifacts (Kendall and Dearden 2018). This challenge is a concern to new PD agendas (Bødker and Kyng, 2018) as creating means for people of different hierarchical positions to discuss on an equal footing is never a trivial undertaking, but helps PD contributions along their core goals;

- Participatory practices are a conflictual environment: in a participatory practice, each stakeholder has different needs and goals, making PD a discipline that needs to deal with conflict if it seeks to tension power relations and change who gets to decide technology. Considering conflict as a driving force for change can make designers integrate them to the practices (Kendall and Dearden 2018), though some preparation should always be in order for dealing with them (Akama and Light 2018). Conflicts represent opportunities for mutual learning among people in the practice space, but can also be hurdles for making meaningful change and promoting democracy (Thinyane et al. 2018). Considering conflicts may point to challenges and opportunities for participation, and not taking any conflict into consideration is a means for abstaining from making political commitments, and would be a repetition of historic HCI agendas, that sought to universalize people as "end-users" (Satchell and Dourish, 2009);

- Ethical Dimension

- Contextual and cultural differences make or break the practice: each person, be it designer or partner, has a personal and cultural history, as well as some life experience before participating in a project (Feng and Feenberg 2008). In collaborating with many people, each singular personal history may contribute with information for co-design (Huybrechts et al., 2018b). Thinking about why interpersonal conflicts exist, for example, may direct participation towards a more ethic form, that would fall for PD's historic pitfalls of exploitation, manipulation, and illusion (Muller et al., 1997). For example, Kendall and Dearden (2018) explore how historical processes of colonialism influence PD projects;

- Interpersonal interactions in a participatory practice matter: the way which a designer responds to conflicts and unexpected situations in practice is a point considered in new PD agendas (Akama and Light 2018). Interpersonal relationships which occur during practice influence the results, and building trust is an important part of working with a partner community 
(Spiel et al., 2018). Each detail in the practice's procedure influences the relations between people in practice, and it is possible for the designer to prepare for working on the community (Akama and Light 2018). However, this effort of preparation is not a guarantee of success, as some interactions that are not usually documented in technical reports (e.g. appearance) may still change project results (Spiel et al., 2018) (Kendall and Dearden 2018);

- Technological dimension

- A participatory project may not fit to paper format: durability is an important factor for PD projects (Kendall and Dearden 2018), and is key for focusing contributions towards more ambitions societal and technological changes (Bødker and Kyng, 2018). Enabling meaningful and lasting change is a challenge for PD, as research and participation are situated inside extremely complex social systems (Huybrechts et al., 2018b). The surroundings, past issues, practice results, consequences, and people involved in a participatory process may not entirely fit in a paper format, specially considering durable participatory processes are meant to continue without the designer's presence and intervention; and

- Mutual learning emerges from practice: participation is a means for designers and partner communities to mutually learn about technology (e.g. how to build artifacts that make sense and tackle real issues, how to think about the consequences of a technology to a community, what is each community's history, how is their daily lives), these moments of learning can emerge from unexpected moments during conversation (Spiel et al., 2018) (Akama and Light 2018). This unexpected learning can help adjust ongoing and future practices, and can inform partner communities about how to produce technology, even without the designer's say. Technological education is an important form PD researchers have for returning results to the communities.

\section{CONSIDERATIONS}

This paper sought to comprehend how current PD practitioners perceive themselves in their practices amidst a moment of renewal and re-thinking of participation. The paper places the designer's comprehension in three dimensions, ethics, and exposes important points of reflection in each dimension. We identified that using participation to produce artifacts is losing space in favor of applying PD with shifted core goals, such as building legitimate democratic dialogue spaces and promoting technological education. The durability and sustainability of PD projects is also a prominent issue and concern, and is considered an important factor for making contributions that are meaningful and lasting.

The three dimensions for situating designers in their practices can be used as a lens to approach the issues exposed by Bødker and Kyng (2018). We made an exercise in how thinking in the three dimensions and acting on the suggestions might help counter issues the authors signaled in current PD projects:

1. The excessive focus on here-and-now is countered by considering PD as being more than the collaborative production of artifacts, as shown by Thinyane et al. (2018), and by thinking in project durability, as exposed by Huybrechts et al. (2018). Thinking about the future, however, does not abstain designers from co-designing artifacts that work, as working artifacts build trust in the partner community and give more meaning to participatory practices. The technological dimension discussed in the previous section can be an instrument to mitigate this issue, as to help active efforts to consider the consequences of a practice or a project;

2. The low technological ambitions emerge as a consequence of thinking about technology as only artifacts, not as a way for employing rationality to think about new ways to transform reality. Considering technological education as an important means for giving back to partners is in itself a higher technological ambition (Lodato and DiSalvo, 2018). PD has the potential to offer more than better artifacts, and it can operate on callings to change politics and technology according to the participants' needs, without the need to design technology that would not necessarily be accessible to them (Thinyane et al., 2018). The technological and political dimensions may be useful towards thinking about this issue, as they relate to recognize technology as more than artifacts;

3. The non-confrontational do-gooding is a consequence of an ideology in PD research that considers it as being inherently good, and above discussions about technological neutrality. Thinking about power relations, history, and the surroundings of practice and design may help seeing PD as part of a 
productive system where disempowerment occur, breaking the illusion of goodness the field carries (Spiel et al.,2018)) (Lodato and DiSalvo, 2018). The ethical and political dimensions are important to dismiss this ideology, as they consider PD not as inherently good, or even ethical. Promoting empowerment through practice is the responsibility of designers, and understanding where disempowerment stems from is an important consideration for a legitimate process;

4. The politics being reduced to ethics is tensioned by thinking about the personal histories of each partner, and about PD as a space for conflict. Approaches with agonistic views are common in PD research (Björgvinsson et al., 2010), and present ways for embracing conflict as a critical and essential part to the quality of a contribution. The political dimension considers participation as a space for contention, and we believe this is a way to disentangle politics and ethics.

The set of suggestions this paper presents indicates that the international PD community has intent to advance their agendas towards renewed political concerns. This paper's contribution is on punctuating them in a concise and practice-oriented way, enabling designers to express their positionings explicitly in relation to their research agendas. In practice, the differences between agendas exist in implementation details, which are important as they influence practice results. The suggestions here presented can be expanded upon when more projects are reported. This renewal of agendas and advancements of the discipline are still only beginning, and we cannot predict where this revitalization is headed towards.

Proposing techniques and participatory practices that consider all dimensions is an opportunity for future works, as the applicability of agendas made by other communities may be limited by cultural and social factors in different locales. Comprehending the current situation of PD agendas in each locale is a need for proposing novel ways for designing with people, building not only computer systems that work according to the partner community's needs, but also dialogue and democracy spaces, as well as education about technological change and its implications.

\section{REFERENCES}

Akama, Y. and Light, A., 2018. Practices of readiness: Punctuation, poise and the contingencies of participatory design. Proceedings of the 15th Participatory Design Conference: Full Papers - Volume 1. New York, NY, pp. 13:1-13:12.

Beyer, H. and Holtzblatt, K., 1998. Contextual Design: Defining Customer-centered Systems. Morgan Kaufmann Publishers Inc., San Francisco, USA.

Bjerknes, G. and Bratteteig, T., 1995. User participation and democracy: A discussion of scandinavian research on systems development. In Scandinavian Journal of Information Systems, 7(1):73-98.

Björgvinsson, E. et al, 2010. Participatory design and "democratizing innovation". Proceedings of the 11th Biennial Participatory Design Conference, pp. 41-50, New York, USA

Boy, Guy A., 1997. The group elicitation method for participatory design and usability testing. Interactions. Vol. 4(2). pp 27-33.

Bødker, S. and Kyng, M., 2018. Participatory design that matters - facing the big issues. ACM Transactions on Computer-Human Interaction, Vol. 25(1), pp 4:1-4:31.

Bødker, S. and Grønbæk, K., 1992. Design in action: From prototyping by demonstration to cooperative prototyping. Design at Work: Cooperative Design of Computer Systems, pp 197-218.

Ehn, P., 1990. Work-Oriented Design of Computer Artifacts. L. Erlbaum Associates Inc., Hillsdale, USA.

Emspak, F., 1993. Workers, unions, and new technology. In Participatory Design-Principles and Practices, pp 13-26. CRC Press, Florida, USA

Feenberg, A., 2000. From essentialism to constructivism: Philosophy of technology at the crossroads. Technology and the good life, pp 294-315.

Feng, P. and Feenberg, A., 2008. Thinking about Design: Critical Theory of Technology and the Design Process, pp 105-118. Springer Netherlands, Dordrecht.

Halskov, K. and Hansen, N. B., 2015. The diversity of participatory design research practice at PDC 2002-2012. International Journal of Human-Computer Studies, Vol. 74, pp 81- 92.

Huybrechts, L. et al, 2018. Work, labour and action: The role of participatory design in (re)activating the political dimension of work. Proceedings of the 15th Participatory Design Conference: Full Papers - Volume 1, pp 1-11, New York, USA.

Huybrechts, L. et al, editors, 2018b. PDC '18: Proceedings of the 15th Participatory Design Conference: Full Papers - Volume 1, New York, USA. 
Kendall, L. and Dearden, A., 2018. Disentangling participatory ict design in socioeconomic development. Proceedings of the 15th Participatory Design Conference: Full Papers - Volume 1, pp 1-12, New York, USA.

Kensing, F. and Blomberg, J.,1998. Participatory design: Issues and concerns. Computer Supported Cooperative Work, Vol. 7, No. 3, pp 167-185.

Korsgaard, H. et al, 2016. Computational alternatives in participatory design: Putting the t back in socio-technical research. Proceedings of the 14th Participatory Design Conference: Full Papers - Volume 1, pp 71-79, New York, USA.

Muller, M. J. et al, 1997. Participatory practices in the software lifecycle. In Helander, M. G., Landauer, T. K., and Prabhu, P. V., editors, Handbook of human-computer interaction, pp 256-300. North-Holland.

Pihkala, S. and Karasti, H., 2018. Politics of mattering in the practices of participatory design. Proceedings of the 15th Participatory Design Conference: Short Papers, Situated Actions, Workshops and Tutorial - Volume 2, pp 13:1-13:5, New York, USA.

Satchell, C. and Dourish, P., 2009. Beyond the user: Use and non-use in hci. Proceedings of the 21st Annual Conference of the Australian Computer-Human Interaction Special Interest Group: Design: Open 24/7, pp 9-16, New York, USA.

Schuler, D. and Namioka, A., editors, 1993. Participatory Design: Principles and Practices. L. Erlbaum Associates Inc., Hillsdale, USA.

Spiel, K. et al, 2018. Microethics for participatory design with marginalised children. Proceedings of the $15^{\text {th }}$ Participatory Design Conference: Full Papers - Volume 1, pages 17:1-17:12, New York, USA.

Spinuzzi, C., 2002. A scandinavian challenge, a us response: Methodological assumptions in scandinavian and us prototyping approaches. Proceedings of the 20th Annual International Conference on Computer Documentation, SIGDOC '02, pp 208-215, New York, USA.

Sundblad, Y., 2011. Utopia: Participatory design from scandinavia to the world. In Impagliazzo, J., Lundin, P., and Wangler, B., editors, History of Nordic Computing 3, pp 176-186. Springer Berlin Heidelberg. Berlin, Heidelberg.

Teli, M. et al, 2018. Institutioning the common: The case of commonfare. Proceedings of the 15th Participatory Design Conference: Full Papers - Volume 1, pp 6:1-6:11, New York, USA.

Thinyane, M. et al, 2018. Critical participatory design: Reflections on engagement and empowerment in a case of a community based organization. Proceedings of the 15th Participatory Design Conference: Full Papers - Volume 1, pp 2:1-2:10, New York, USA. 